NUMERICAL REPRESENTATION OF ACYCLIC PREFERENCES*

Begoña Subiza**

WP-AD 93-09

* Thanks are due to C. Herrero and J.E. Peris for helpful comments. Financial support from the DGICYT under project PB 92-0342 is gratefully acknowledged.

** University of Alicante. 
Editor: Instituto Valenciano de Investigaciones Económicas, S.A. Primera Edición Octubre 1993. ISBN: 84-482-0324-0 Depósito Legal: V-3547-1993 Impreso por KEY, S.A., Valencia. Cardenal Benlloch, 69, 46021-Valencia. Printed in Spain. 


\section{NUMERICAL REPRESENTATION OF ACYCLIC PREFERENCES}

\section{Begoña Subiza}

\section{A B S T R A C T}

In this paper, it is shown that, under certain conditions on a preference relation defined on a set $X$, there exists a numerical representation by means of set-valued real functions. This kind of representation extends the usual utility function as well as the representation by means of two real functions. The continuity of this representation is also discussed. 



\section{1.- INTRODUCTION}

Economists have usually assumed that the agent's preferences are representable by means of a real utility function $u$, in such a way that $\mathrm{x}$ is preferred to $\mathrm{y}$ if and only if $u(\mathrm{x})>u(\mathrm{y})$. Assuming that this kind of representation exists then the agent's preference is a preorder.

Looking for a representation of preferences less restrictive than preorders, Scott and Suppes (1958), Fishburn (1973), Chateauneuf (1987) and Bridges (1983 a, b, 1985) analize the case in which the preference relation is representable by means of two real functions $u, v$ in such a way that $\mathrm{x}$ is preferred to $\mathrm{y}$ if and only if $u(\mathrm{x})>v(\mathrm{y})$. The existence of the previous numerical representation implies that the preference relation is an interval order.

In Herrero and Subiza (1991) a new numerical representation by means of set-valued real functions is presented (utility correspondence). The existence of a utility correspondence implies that the agent's preference is acyclic and, as we can see in the aforementioned work, this numerical representation provides a characterization of acyclic preference relations on countable sets.

The aim of this paper is to give simple conditions for the existence of such a utility correspondence in more general sets. We also study the continuity of this representation when $\mathrm{X}$ is a topological space. The paper is organized as follows: in Section 2, we present some definitions and 
known results, Section 3 is devoted to the existence of utility correspondence for acyclic preference relations on an uncountable set $\mathrm{X}$, and finally, in Section 4, the continuity of the representation is discussed.

\section{2.- PRELIMINARIES}

Let, be a preference (asymmetric) relation on a set $\mathrm{X}$. Then other binary relations on $\mathrm{X}$ are defined from \}:

$\mathrm{x} ? \mathrm{y}$ if and only if not $\mathrm{y}>\mathrm{x}$ (the preference-indifference )

$\mathrm{x}$ ) $\mathrm{y}$ if and only if there exist

$$
\left.\left.\mathrm{x}_{1}, \mathrm{x}_{2}, \ldots, \dot{\mathrm{x}}_{\mathrm{n}} \in \mathrm{X} \mid \mathrm{x}=\mathrm{x}_{1}\right\} \mathrm{x}_{2}\right\} \ldots, \mathrm{x}_{\mathrm{n}}=\mathrm{y} \text { (the transitive closure) }
$$

$\mathrm{x} \approx \mathrm{y}$ if and only if neither $\mathrm{x}\} \mathrm{y}$ or $\mathrm{y} \nLeftarrow \mathrm{x}$

$\mathrm{x} \approx \mathrm{y}$ if and only if not $\mathrm{x} \approx \mathrm{y}$

The preference-indifference relation turns out to be reflexive and complete; when the initial relation, is acyclic, the transitive closure is a transitive preference relation, and if $\}$ is transitive, then $\}=\}$.

\section{Definition 1}

Let, be a preference relation defined on a set $\mathrm{X}$, and $\mu: \mathrm{X} \longrightarrow \mathbb{R}$ a correspondence. We shall say that $\mu$ is a utility correspondence for the preference relation, if:

(a) $\forall x \in X, \mu(x)$ is nonempty and bounded

(b) $\mathrm{x}, \mathrm{y} \longleftrightarrow \mu(\mathrm{x}) \cap \mu(\mathrm{y})=\varnothing$, and $\sup \mu(\mathrm{x})>\sup \mu(\mathrm{y})$ 
When a binary relation can be represented by a utility correspondence, this preference relation is necessarily acyclic for any set of alternatives (Herrero \& Subiza, 1991). In particular, when the set of alternatives on which the relation is defined is countable, the converse result also holds:

Propasition 1 (Herrero \& Subiza, 1991)

Let $X$ be a countable set, and, an acyclic preference relation on $X$. Then, there exists a utility correspondence for \}.

In the case the opportunity set is uncontable it is not possible, in general, to obtain a utility correspondence for an acyclic relation. To see this consider the lexicographical order in $\mathbb{R} \times\{0,1\}$ and suppose a utility correspondence $\mu$ for this preference relation. Since this relation has no indifferent elements, then $\mathrm{u}(\mathrm{x})=$ sup $\mu(\mathrm{x})$ must be a utility function which does not exist in this case. So, additional conditions are required in order to get this kind of representation for uncountable opportunity sets. Furthermore, when the preference relation is defined on a topological space, it is useful to find conditions on the continuity of the supremum function.

In order to get existence and continuity of numerical representations for preorders or interval-orders on topological spaces, two different types of conditions are used in the literature. The first one refers to continuity and the second one deals with separability. 


\section{Definition 2}

The preference relation, defined on a topological space $\mathrm{X}$ is said to be lower continuous if the lower contour sets are open, that is if

$$
\mathscr{L}(\mathrm{x})=\{z \in X \mid z \in \mathrm{x}\} \text { is open } \forall \mathrm{x} \in \mathrm{X}
$$

On the other hand, several conditions on the separability of the preference relation appear. The idea in all of them is based on the existence of a countable subset $\mathrm{D}$ contained in $\mathrm{X}$, in such a way that when $\mathrm{X}$ is preferred to $\mathrm{y}$ there is some element of $\mathrm{D}$ between $\mathrm{x}$ and $\mathrm{y}$. In order to use uniform notation we consider the following definitions:

\section{Definition 3}

The relation, is weakly separable if there exists a countable set $D \subseteq X$ such that whenever $x$, y there are $d_{1}, d_{2} \in D$ such that

$$
x>d_{1}>d_{2}>y \text {. }
$$

\section{Definition 4}

The relation $\}$ is separable if there exists a countable set $D \subseteq X$ such that whenever $\mathrm{x}$, $\mathrm{y}$ there is some $\mathrm{d} \in \mathrm{D}$ such that

$$
\text { x r d r y. }
$$

Obviously, separability implies weak separability. In particular, when the relation is a preorder, both conditions are equivalent. In the literature the property in Definition 3 is sometimes called strong separability (see for instance Chateauneuf, 1987). Definition 4 can be found in Peleg (1970). 


\section{3.- EXISTENCE OF UTILITY CORRESPONDENCE}

We obtain several results about the existence of the utility correspondence, depending on the conditions imposed on the set $\mathrm{X}$.

Thearem 2

Let be an acyclic preference relation on a set $X$, with $^{(1)}|X| \leq{ }_{1} \chi$, such that the transitive closure is weakly separable. Then, there is a utility correspondence for .

\section{$\underline{\text { Proof }}$}

Since $|\mathrm{X}| \leq \chi_{1}$, there is an injection $\alpha: \mathrm{X} \times \mathrm{X} \rightarrow[0,1]$ and we can take then the correspondence $\mu: X \longrightarrow \mathbb{R}$ defined by

$$
\mu(\mathrm{x})=\{\alpha(\mathrm{x}, \mathrm{y}), \alpha(\mathrm{y}, \mathrm{x}) \quad \forall \mathrm{y} \mid \mathrm{y} \sim \mathrm{x}, \mathrm{y} \neq \mathrm{x}\} \cup\{\mathrm{u}(\mathrm{x})\}
$$

where $u(x)$ is constructed in the following way:

since the transitive closure ") is weakly separable, there is a countable set $B=\left\{b_{k}\right\} \subseteq X$ providing the separability then, we define

$$
u(x)=2+\sum_{b k x} \frac{1}{5^{k}}
$$

Therefore, if $\mathrm{x} \sim \mathrm{y}$, then

$$
\alpha(\mathrm{x}, \mathrm{y}), \alpha(\mathrm{y}, \mathrm{x}) \in \mu(\mathrm{x}) \cap \mu(\mathrm{y})
$$

(1) $|x|$ denotes the cardinal of set $x$, and ${ }_{1} \chi=|\mathbb{R}|$. 
On the other hand, if $\mu(\mathrm{x}) \cap \mu(\mathrm{y}) \neq \varnothing$, then either $\mathrm{u}(\mathrm{x})=\mathrm{u}(\mathrm{y})$ or $\mathrm{z}, \mathrm{z}^{\prime}$ in $\mathrm{X}$ exist such that, $\mathrm{z} \sim \mathrm{x}, \mathrm{z}^{\prime} \sim \mathrm{y}$, in such a way that one of the next possibilities holds true

$$
\begin{aligned}
& \alpha(x, z)=\alpha\left(y, z^{\prime}\right) \quad \Rightarrow \quad x=y, z=z^{\prime} \\
& \alpha(x, z)=\alpha\left(z^{\prime}, y\right) \quad \Rightarrow \quad z=y, x=z^{\prime} \\
& \alpha(z, x)=\alpha\left(y, z^{\prime}\right) \quad \Rightarrow \quad z=y, x=z^{\prime} \\
& \alpha(z, x)=\alpha\left(z^{\prime}, y\right) \quad \Rightarrow \quad x=y, z=z^{\prime}
\end{aligned}
$$

In all of these cases $\mathrm{x} \sim \mathrm{y}$ and then $\mu$ is a utility correspondence for .

As an immediate consequence of the former result we now obtain the following one for separable Hausdorff spaces, since its cardinality is smaller than $\chi_{1}$.

\section{Garallary 3}

Let $\mathrm{X}$ be a connected and separable Hausdorff space and, an acyclic preference relation on $\mathrm{X}$ such that its transitive closure is weakly separable. Then, a utility correspondence exists for ).

If we now consider stronger conditions on the preference relation, it is possible to obtain an existence result without requiring any property on the set of alternatives. Let us consider, thus, the following definition. 


\section{Definition 5}

Assume an acyclic and separable relation defined on a set $\mathrm{X}$. Then a countable subset $D$ of $X$ exists such that if $x$, $y$ then there is $d \in D$ with $\mathrm{x}$, d r y. Let us consider the following sets:

$$
\begin{aligned}
& D(\mathrm{x}, \mathrm{y})=\{\mathrm{d} \in \mathrm{D} \mid \mathrm{x} \| \mathrm{d}\} \mathrm{y}\} \\
& \mathcal{F}(\mathrm{x}, \mathrm{y})=\{\mathrm{d} \in \mathrm{D} \mid \mathrm{d} \sim \mathrm{x}, \mathrm{d} \sim \mathrm{y}\}
\end{aligned}
$$

We will say that the relation satisfies property $(\mathrm{P})$ for the set $\mathrm{D}$ if given $x, y, z, z^{\prime}$ such that:
(1) $x \sim z, y \sim z^{\prime}$
(2) $\mathrm{x}\} z, y \ll z$
(3) $\mathcal{D}(\mathrm{x}, \mathrm{z})=\mathcal{D}\left(\mathrm{z}^{\prime}, \mathrm{y}\right)$
(4) $\mathcal{G}(\mathrm{x}, \mathrm{z})=\mathscr{g}\left(\mathrm{y}, \mathrm{z}^{\prime}\right)$

then, $\mathrm{x}$ and $\mathrm{y}$ are indifferent.

Conditions (1) and (2) in the above definition consider elements $x, z$ and $y, z$ ' which are indifferent under the initial relation, but not indifferent under its transitive closure. Thus, property $(P)$ is trivially fulfilled for any $D$ if the preference relation, is transitive since, in this case, conditions (1) and (2) may not be satisfied simultaneously (notice that $)=$ s). Conditions (3) and (4) mean that for any $d$ in the countable set D

$$
\begin{aligned}
& \text { (3) } \mathrm{x}\} \mathrm{d}\}\} \mathrm{z} \Leftrightarrow \mathrm{z}\} \mathrm{d}\} y \\
& \text { (4) } \mathrm{d} \sim \mathrm{x}, \mathrm{d} \sim \mathrm{z} \Leftrightarrow \mathrm{d} \sim \mathrm{z}^{\prime}, \mathrm{d} \sim \mathrm{y}
\end{aligned}
$$


For acyclic relations, whether or not this property is fulfilled depends both on the relation and on the countable set D. Let us now consider two different cases in which we deal with the following relation on a subset $\mathrm{X}$ of $\mathbb{R}_{+}^{2}$

$$
\mathrm{x}, \mathrm{y} \Leftrightarrow\|\mathrm{x}\|>\|\mathrm{y}\| \text { and }\|\mathrm{x}-\mathrm{y}\|>2
$$

This relation is separable; in fact we can choose several countable sets which do the job. If $D=X \cap \mathbb{Q} \times \mathbb{Q}$, if conditions (1)-(4) hold, then $x=z^{\prime}$ and $\mathrm{y}=\mathrm{z}$ because for all $\mathrm{d}$ in $\mathbb{Q} \times \mathbb{Q}$

$$
\begin{aligned}
& \|\mathrm{x}\|>\|\mathrm{d}\|>\|\mathrm{y}\| \text { if and only if }\|\mathrm{y}\|>\|\mathrm{d}\|>\left\|\mathrm{z}^{\prime}\right\| \\
& \|\mathrm{x}-\mathrm{d}\| \leq 2 \text { and }\|\mathrm{z}-\mathrm{d}\| \leq 2 \text { if and only if }\|\mathrm{y}-\mathrm{d}\| \leq 2 \text { and }\left\|\mathrm{z}^{\prime}-\mathrm{d}\right\| \leq 2 .
\end{aligned}
$$

Thus, property (P) is fulfilled for D.

On the other hand, we can consider the countable set

$$
D^{\prime}=\left\{\left(x_{1}, x_{2}\right) \in \mathbb{Q} \times \mathbb{Q} \mid x_{1}=x_{2} \text { or } x_{2}=32 x_{1} \text { or } x_{1}=32 x_{2}\right\}
$$

and in this case there are $\mathrm{x}, \mathrm{y} \in \mathrm{X}$ satisfying conditions (1)-(4) which are not indifferent (for example we can take $x=(4,11), \quad z=(4,10)$, $\left.y=(10,4), z^{\prime}=(11,4)\right)$. Thus, property $(P)$ is not fulfilled for $D^{\prime}$.

This property (P) also depends on the preference relation, as we can see by means of the following example. Let $y_{1}$ and $y_{2}$ be preference relations defined on the set $X=\{f:[0,1] \longrightarrow \mathbb{R} \mid f$ is continuous $\}$ 


$$
\begin{aligned}
& f_{{ }_{1}{ }_{1} g} \Leftrightarrow \max f(x)>\max g(x) \text { and }|f(0)-g(0)|>1 \\
& f^{f_{2} g} \Leftrightarrow \max f(x)>\max g(x) \text { and } \max |f(x)-g(x)|>1
\end{aligned}
$$

$y_{1}$ and $\gamma_{2}$ are separable relations, where $\mathrm{D}$ can be taken as

$$
D=\left\{r:[0,1] \longrightarrow \mathbb{R} \mid r(x)=q x+q^{\prime}, q, q^{\prime} \in \mathbb{Q}\right\}
$$

$\jmath_{1}$ satisfies property (P) for set D, but ${ }_{2}$ does not do so it for the same set.

If conditions (1)-(4) of property (P) hold for some $D$, then some additional elements turn out to be indifferent, as we can see in the following lemma.

\section{Lemma 4}

Let s be an acyclic and separable preference relation and let $D$ be the countable subset which provides the separability. Then, if $x, y, z, z$ ' are such that:
(1) $x \sim z, y \sim z^{\prime}$
(2) $\mathbf{x}\} \mathbf{z}, \mathbf{y} \ll \mathbf{z}$
(3) $D(\mathbf{x}, \mathbf{z})=D\left(\mathbf{z}^{\prime}, \mathbf{y}\right)$
(4) $\mathscr{f}(\mathbf{x}, \mathbf{z})=\mathscr{f}\left(\mathbf{y}, \mathbf{z}^{\prime}\right)$

then, $\mathbf{x} \sim \mathbf{z}^{\prime}, \mathbf{y} \sim \mathbf{z}$

\section{$\underline{\text { Proof }}$}

Since $\mathrm{x}$ \}) $\mathrm{z}$, there is some $\mathrm{d} \in \mathrm{D}$ such that

$$
\text { x }\} d \text { d } z
$$

Then, by condition (3), $\mathcal{D}(\mathrm{x}, \mathrm{z})=\mathcal{D}\left(\mathrm{z}^{\prime}, \mathrm{y}\right)$,

$$
\text { z' 3) d ") y }
$$


If $x ; z^{\prime}$ there exists $d_{1} \in D$ such that $x ; d_{1}, z^{\prime}$, and then

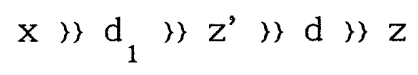

Thus, $\mathrm{d}_{1} \in D(\mathrm{x}, \mathrm{z}), \mathrm{d}_{1} \notin D\left(\mathrm{z}^{\prime}, \mathrm{y}\right)$, against condition (3). In a similar way, we can see that it cannot be the case that $x<z$, and therefore

$$
\mathrm{x} \sim \mathrm{z}^{\prime}
$$

With an identical argument,

$$
y \sim z
$$

In order to get the existence of the utility correspondence for an acyclic relation on a more general set $X$, we will see firstly that separable partial order relations can be represented by means of a utility correspondence.

\section{Lemma 5}

Let, be a separable partial order relation on a set $X$. Then, a utility correspondence for , exists.

\section{Proof}

Let $D=\left\{d_{i}, i \in \mathbb{N}\right\}$ be a countable set, providing the separability of the relation, and let

$$
\mathrm{D}(\mathrm{x})=\left\{\mathrm{n} \in \mathbb{N} \mid \mathrm{d}_{\mathrm{n}}\{\mathrm{x}\} \quad \overline{\mathrm{D}}(\mathrm{x})=\left\{\mathrm{n} \in \mathbb{N} \mid \mathrm{d}_{\mathrm{n}}\{\mathrm{x}\}\right.\right.
$$

We now define the following functions:

$$
b(x)=\left\{\begin{array}{ccc}
\sum_{n \in \bar{D}(x)} \frac{1}{5^{n}} & \text { if } & \bar{D}(x) \neq \varnothing \\
0 & \text { if } & \bar{D}(x)=\varnothing
\end{array}\right.
$$




$$
\begin{aligned}
& f(x)=\left\{\begin{array}{ccc}
\sum_{n \in D(x)} \frac{1}{5^{n}} & \text { if } & D(x) \neq \varnothing \\
0 & \text { if } & D(x)=\varnothing
\end{array}\right. \\
& u(x)=f(x)+1
\end{aligned}
$$

By using these functions, we define the correspondence $\mu: X \longrightarrow \mathbb{R}$ as

$$
\mu(\mathrm{x})=\{\mathrm{b}(\mathrm{x})+\mathrm{b}(\mathrm{y}), \forall \mathrm{y} \sim \mathrm{x}, \mathrm{y} \neq \mathrm{x}\} \cup\{\mathrm{u}(\mathrm{x})\}
$$

Note, firstly, that

$$
\forall \mathrm{X} \in \mathrm{X} \quad \mu(\mathrm{x}) \subseteq[0,2]
$$

and $\mu(\mathrm{x})$ is nonempty. Moreover, if $\mathrm{x} \sim \mathrm{y}$ then

$$
\mathrm{b}(\mathrm{x})+\mathrm{b}(\mathrm{y}) \in \mu(\mathrm{x}) \cap \mu(\mathrm{y})
$$

and $\mu(\mathrm{x}) \cap \mu(\mathrm{y}) \neq \varnothing$. Conversely, if $\mu(\mathrm{x}) \cap \mu(\mathrm{y}) \neq \varnothing$, then either

$$
f(x)=f(y)
$$

or $\mathrm{z}, \mathrm{z}^{\prime}$ can be found such that $\mathrm{z} \sim \mathrm{x}, \mathrm{z}^{\prime} \sim \mathrm{y}$, and

$$
b(x)+b(z)=b(y)+b\left(z^{\prime}\right)
$$

In both cases we conclude $\mathrm{x} \sim \mathrm{y}$, due to the separability of the relation.

Finally, if $\mathrm{x}, \mathrm{y}$, then $\mu(\mathrm{x}) \cap \mu(\mathrm{y})=\varnothing$, and, the relation being transitive, if $d_{n}<y$, then $d_{n}<x$. Thus

$$
f(x) \geq f(y)
$$

Furthermore, by the separability condition, $\exists \mathrm{d}_{\mathrm{m}} \in \mathrm{D} \mid \mathrm{x}, \mathrm{d}_{\mathrm{m}}, \mathrm{y}$, and then $f(x)>f(y)$ that is,

$$
\mathrm{u}(\mathrm{x})=\sup \mu(\mathrm{x})>\mathrm{u}(\mathrm{y})=\sup \mu(\mathrm{y})
$$


Therefore, $\mu(\mathrm{x})$ is a utility correspondence for the relation 3 .

By using property (P), and the former lemmas, we can prove the following result:

Thearem 6

Let ) be a separable preference relation on a set $X$, such that for the countable set $\mathrm{D} \subseteq \mathrm{X}$, which provides the separability of the relation, property $(P)$ is fulfilled. Then, there exists a utility correspondence for , if, and only if,, is acyclic.

$\underline{\text { Proof }}$

Since, is acyclic and separable, its transitive closure turns out to be a separable partial order relation. Then, from the previous lemma, a utility correspondence for ") exists

$$
\mu_{1}: X \longrightarrow \mathbb{R} \text { such that } \mu_{1}(\mathrm{X}) \subseteq[0,2]
$$

Let now $\mu: \mathrm{X} \longrightarrow \mathbb{R}$ be the correspondence defined by

$$
\mu(\mathrm{x})=\mu_{1}(\mathrm{x}) \cup \mu_{2}(\mathrm{x}) \cup\{\mathrm{u}(\mathrm{x})\}
$$

where

$$
\begin{aligned}
& \mu_{2}(\mathrm{x})=\left\{3+\sum_{\mathrm{i} \mid \mathrm{d}_{\mathrm{i}} \in \mathcal{D}(\mathrm{x}, \mathrm{y})}(1 / 5)^{\mathrm{i}}+\sum_{\mathrm{j} \mid \mathrm{d}_{\mathrm{j}} \in \mathcal{I}(\mathrm{x}, \mathrm{y})}(1 / 7)^{\mathrm{j}} \quad \forall \mathrm{y} \sim \mathrm{x}, \mathrm{y} \approx^{\mathrm{c}} \mathrm{x}\right\} \\
& \mathrm{u}(\mathrm{x})=\sup \mu_{1}(\mathrm{x})+6
\end{aligned}
$$

Note that $\forall \mathrm{x}, \mu(\mathrm{x}) \subseteq[0,8], \mu(\mathrm{x}) \neq \varnothing$, and

$$
\mathrm{u}(\mathrm{x})=\sup \mu(\mathrm{x})
$$


If $\mathrm{x}$ \} $\mathrm{y}$, then $\mathrm{x}$ ) $\mathrm{y}$, and $\sup \mu_{1}(\mathrm{x})>\sup \mu_{1}(\mathrm{y})$. Thus

$\sup \mu(\mathrm{x})>\sup \mu(\mathrm{y})$.

It is then only necessary to prove that

$$
\mathrm{x} \sim \mathrm{y} \longleftrightarrow \mu(\mathrm{x}) \cap \mu(\mathrm{y}) \neq \varnothing
$$

If $\mathrm{x} \sim \mathrm{y}$ then

$$
\mathrm{x} \approx \mathrm{y} \Rightarrow \mu_{1}(\mathrm{x}) \cap \mu_{1}(\mathrm{y}) \neq \varnothing
$$

or

$$
\mathrm{x} \approx^{\mathrm{c}} \mathrm{y} \Rightarrow \mu_{2}(\mathrm{x}) \cap \mu_{2}(\mathrm{y}) \neq \varnothing
$$

and therefore, $\mu(\mathrm{x}) \cap \mu(\mathrm{y}) \neq \varnothing$.

Conversely, if $\mu(\mathrm{x}) \cap \mu(\mathrm{y}) \neq \varnothing$, one of the next possibilities must hold:

$$
\begin{aligned}
& \text { (1) } u(x)=u(y) \\
& \text { (2) } \mu_{1}(\mathrm{x}) \cap \mu_{1}(\mathrm{y}) \neq \varnothing \\
& \text { (3) } \mu_{2}(\mathrm{x}) \cap \mu_{2}(\mathrm{y}) \neq \varnothing
\end{aligned}
$$

If $(1)$ or $(2)$ hold, then $\mathrm{x} \approx \mathrm{y}$, which implies that $\mathrm{x} \sim \mathrm{y}$.

Finally, in the case whereby (3) holds, there are $z, z^{\prime} \in X$ such that:

$$
\begin{aligned}
& x \sim z, y \sim z^{\prime}, x \approx^{c} z, y \approx^{c} z^{\prime} \\
& \sum_{i \mid d_{i} \in \mathcal{D}(x, z)}(1 / 5)^{i}+\sum_{j \mid d_{j} \in \mathcal{F}(x, z)}(1 / 7)^{j}=\sum_{i \mid d_{i} \in \mathcal{D}\left(z^{\prime}, y\right)}(1 / 5)^{i}+\sum_{j \mid d_{j} \in \mathcal{F}\left(z^{\prime}, y\right)}(1 / 7)^{j}
\end{aligned}
$$

then,

$$
\begin{aligned}
\sum_{i \mid d_{i} \in \mathcal{D}(x, z)}(1 / 5)^{i} & =\sum_{i \mid d_{i} \in \mathcal{D}\left(z^{\prime}, y\right)}(1 / 5)^{i} \\
\sum_{j \mid d_{j} \in \mathcal{F}(x, z)}(1 / 7)^{j} & =\sum_{j \mid d_{j} \in \mathcal{F}\left(z^{\prime}, y\right)}(1 / 7)^{j}
\end{aligned}
$$


and therefore,

$$
\mathcal{D}(\mathrm{x}, \mathrm{z})=\mathcal{D}\left(\mathrm{z}^{\prime}, \mathrm{y}\right) ; \quad g(\mathrm{x}, \mathrm{z})=\mathscr{g}\left(\mathrm{z}^{\prime}, \mathrm{y}\right)
$$

From Lemma 1 and property $(\mathrm{P})$ we have

$$
\mathrm{x} \sim \mathrm{y}
$$

\section{4.- CONTINUITY OF THE SUPREMUM FUNCTION}

As far as results which guarantee the continuity of the supremum function $\mathrm{u}(\mathrm{x})$ are concerned, we have the following:

\section{Thearem 7}

If $X$ is a topological space and, is a preference relation on $X$ such that it is

(i) acyclic

(ii) separable, fulfilling property (P)

(iii) its transitive closure is lower continuous

(iv) its transitive closure holds that cl[ $\mathscr{L}(\mathbf{y})] \subseteq \mathscr{L}(\mathbf{x})$ when $\mathbf{x}\}$ y.

Then, there exists a utility correspondence whose supremum function is continuous.

Proof

In order to prove this result, it is sufficient to modify the utility correspondence of the former theorem in its supremum function, which is 
then substituted for another one for which, by using the new conditions, continuity may be guaranteed.

By using the above result, we have that there is a utility correspondence $\mu(\mathrm{x})=\mu_{1}(\mathrm{x}) \cup \mu_{2}(\mathrm{x}) \cup\{\mathrm{u}(\mathrm{x})\}$ with

$$
\begin{aligned}
& \mu_{1}(\mathrm{x}) \subseteq[0,2] \\
& \mu_{2}(\mathrm{x}) \subseteq[3,5] \\
& \mathrm{u}(\mathrm{x})=\sup \mu_{1}(\mathrm{x})+6 \in[6,8] .
\end{aligned}
$$

Let $\mathcal{G} \subseteq \mathrm{D} \times \mathrm{D}$ be, such that $\left(\mathrm{d}_{\mathbf{k}}, \mathrm{d}_{\mathbf{k}}^{\prime}\right) \in \mathscr{G}$ if, and only if, $\left.\left.\mathrm{d}_{\mathbf{k}}\right\}\right) \mathrm{d}_{\mathbf{k}}^{\prime}$. Since $\}$ is separable we can take the set

$$
\left.\left.D_{k} \subseteq\left\{d \in D \mid d_{k}\right\} d\right\} d_{k}^{\prime}\right\}
$$

infinite countable, completely ordered by the relation "), with neither a first nor a last element. Then, a one-to-one mapping can be defined

$$
\mathrm{g}_{\mathrm{k}}: \mathrm{D}_{\mathbf{k}} \longrightarrow \mathbb{Q} \cap(0,1)
$$

such that $\left.\forall \mathrm{d}, \mathrm{d}^{\prime} \in \mathrm{D}_{\mathrm{k}} \quad \mathrm{d}\right) \mathrm{d}^{\prime} \longleftrightarrow \mathrm{g}_{\mathrm{k}}(\mathrm{d})>\mathrm{g}_{\mathrm{k}}\left(\mathrm{d}^{\prime}\right)$

Let now $u_{k}: X \longrightarrow[0,1]$ be defined in the following way:

$$
u_{k}(x)=\left\{\begin{array}{l}
1 \text { if there is no } d_{k} \in D \text { such that } d \text { \} } x \\
\left.\left.\inf \left\{g_{k}(d) \mid d \in D_{k}, d\right\}\right\} x\right\} \text { otherwise }
\end{array}\right.
$$

Notice first that, if $x$, $y$, then

$$
\mathrm{x} \ll \mathrm{d} \longrightarrow \mathrm{y} \ll \mathrm{d}
$$


and therefore

$$
u_{k}(x) \geq u_{k}(y)
$$

Secondly, we will prove that both $u_{k}^{-1}(\alpha,+\infty)$ and $u_{k}^{-1}(-\infty, \alpha)$ are open sets $\forall \alpha \in \mathbb{R}$.

Let $u_{k}^{-1}(\alpha,+\infty)=\left\{x \in X \mid u_{k}(x)>\alpha\right\}$. If $\alpha \geq 1$, then,

$$
u_{k}^{-1}(\alpha,+\infty)=\varnothing
$$

whereas if $x \in u_{k}^{-1}(\alpha,+\infty)$, then $q, q^{\prime} \in \mathbb{Q} \cap(0,1)$ can be found such that

$$
1 \geq u_{k}(x)>q>q^{\prime}>\alpha
$$

If $g_{\mathbf{k}}(d)=q, g_{k}\left(d^{\prime}\right)=q^{\prime}$, then $\left.d^{\prime}\right\} d^{\prime}$ and we have that

$$
\mathrm{x} \notin \mathscr{L}(\mathrm{d})=\{\mathrm{w} \in \mathrm{X} \mid \mathrm{w}\{\mathrm{d}\}
$$

since $u_{k}(x)>g_{k}(d)$. Thus by condition (iv),

$$
\mathrm{x} \notin \operatorname{cl} \mathscr{L}\left(\mathrm{d}^{\prime}\right) \subseteq \mathscr{L}(\mathrm{d})
$$

and

$$
\mathrm{x} \in \mathrm{V}=\mathrm{X}-\operatorname{cl} \mathscr{L}\left(\mathrm{d}^{\prime}\right)
$$

which is an open set. Furthermore, if $z \in V$, then

$$
u_{k}(z) \geq q^{\prime}>\alpha,
$$

since if $u_{k}(z)<q^{\prime}$ there is $d^{\prime \prime}$ ') $z$, d' $\in D_{k}$, such that

$$
g_{k}\left(d^{\prime \prime}\right)<g_{k}\left(d^{\prime}\right)
$$

and thus

$$
z \text { \& d" « d' }
$$

which implies $z \in \mathscr{L}\left(\mathrm{d}^{\prime}\right)$, against $z \in \mathrm{V}$. Then,

$$
\mathrm{x} \in \mathrm{V} \subseteq \mathrm{u}_{\mathrm{k}}^{-1}(\alpha,+\infty), \mathrm{V} \text { being an open set }
$$

and therefore $u_{k}^{-1}(\alpha,+\infty)$ is open. 
Let now the set $u_{k}^{-1}(-\infty, \alpha)$. If $\alpha \leq 0$, this set is an empty set. On the other hand, if $x \in u_{k}^{-1}(-\infty, \alpha)$, then either

$$
\begin{aligned}
& u_{k}(x)=1, \text { or } \\
& \text { there is some } d \in D_{k} \text { such that } x \ll d, g_{k}(d)<\alpha .
\end{aligned}
$$

In the first case,

$$
u_{k}^{-1}(-\infty, \alpha)=X
$$

and in the second one,

$$
\mathrm{x} \in \mathscr{L}(\mathrm{d}) \text { which is an open set by condition (iii) }
$$

and if $z \in \mathscr{L}(\mathrm{d})$

$$
u_{k}(z) \leq g_{k}(d)<\alpha
$$

then

$$
\mathrm{x} \in \mathscr{L}(\mathrm{d}) \subseteq \mathrm{u}_{\mathrm{k}}^{-1}(-\infty, \alpha)
$$

which is an open set.

Then the function $u_{k}(x)$ is continuous and satisfies that:

$$
\mathrm{x}, \mathrm{y} \longrightarrow \mathrm{u}_{\mathrm{k}}(\mathrm{x}) \geq \mathrm{u}_{\mathrm{k}}(\mathrm{y})
$$

and

$$
u_{k}\left(d_{k}\right)=1, u_{k}\left(d_{k}^{\prime}\right)=0
$$

Let now the function $\hat{\mathrm{u}}: \mathrm{X} \longrightarrow[0,1]$ be defined by:

$$
\hat{\mathrm{u}}(\mathrm{x})=\sum \mathrm{u}_{\mathrm{k}}(\mathrm{x}) 2^{-\mathrm{k}}
$$

and

$$
\bar{u}(x)=\hat{u}(x)+6
$$

As $0 \leq u_{k}(x) 2^{-k} \leq 2^{-k}$, and $u_{k}(x)$ is continuous $\forall k$, then $\bar{u}(x)$ is also continuous. Moreover, if 


$$
\mathrm{x} \text { y } \mathrm{y} \longrightarrow \mathrm{u}_{\mathrm{k}}(\mathrm{x}) \geq \mathrm{u}_{\mathrm{k}}(\mathrm{y}) \quad \forall \mathrm{k} \quad \longrightarrow \quad \overline{\mathrm{u}}(\mathrm{x}) \geq \overline{\mathrm{u}}(\mathrm{y})
$$

But, by the separability condition, there exists some $\left(\mathrm{d}_{\mathrm{r}}, \mathrm{d}_{\mathrm{r}}^{\prime}\right) \in \mathscr{G}$ such that

$$
x>d_{r}, d_{r}^{\prime}, y
$$

Then, $u_{r}(x)=1, u_{r}(y)=0$, and $\bar{u}(x)>\bar{u}(y)$. We can thus take

$$
\mu(\mathrm{x})=\mu_{1}(\mathrm{x}) \cup \mu_{2}(\mathrm{x}) \cup\{\overline{\mathrm{u}}(\mathrm{x})\}
$$

as a utility correspondence for \}, where $\bar{u}(x)=\sup \mu(x)$ is a continuous function.

When a preference relation allows for a utility correspondence, the supremum function is a numerical representation of the type presented in Peleg (1970): if $\mathrm{x}$, $\mathrm{y}$ then $\mathrm{u}(\mathrm{x})=\sup \mu(\mathrm{x})>\mathrm{u}(\mathrm{y})$. Thus we can ensure the existence of such "weak" representation in all the cases in which the utility correspondence exists. In particular, Theorem 7 is a generalization of Peleg's result below

Thearem 8 (Peleg, 1970)

If $\mathrm{X}$ is a topological space and the relation is a lower continuous and separable partial order such that cl $\mathscr{L}(\mathrm{y}) \subseteq \mathscr{L}(\mathrm{x})$ when $\mathrm{x}, \mathrm{y}$. Then, there exists a continuous function $\mathrm{u}: \mathrm{X} \longrightarrow \mathbb{R}$ such that if $\mathrm{x}$, $\mathrm{y}$ then $u(x)>u(y)$. 
R E F E R E N C E S

Bridges, D.S. "A Numerical Representation of Preferences with Intransitive Indifference", Journal of Mathematical Economics 11:25-44 (1983a).

Bridges,D.S. "Numerical Representation of Intransitive Preferences on a Countable Set", Journal of Economic Theory 30:213-217 (1983b).

Bridges, D.S. "Representing Interval-Orders by a Single Real-Valued Function", Journal of Economic Theory 36:149-165 (1985).

Chateauneuf, A. "Continuous Representation of a Preference Relation on a Connected Topological Space", Journal of Mathematical Economics $16: 139-146(1987)$

Debreu, G. "Representation of a Preference Ordering by a Numerical Function", in Decision Processes, ed. by R.M. Thrall, C.H. Coombs and R.L. Davis, New York: Wiley (1954).

Fishburn, P.C. "Interval representations for interval orders and semiorders", Journal of Mathematical Psychology, 7:144-149 (1973).

Fishburn, P.C. "Utility Functions on Ordered Convex Sets", Journal of Mathematical Economics 12:221-232 (1983). 
Herrero,C. \& Subiza, B. " A Characterization of Acyclic Preferences on countable sets", A Discusión, WP-AD-91-01, Instituto Valenciano de Investigaciones Económicas (1991).

Peleg, B. "Utility Functions for Partially Ordered Topological Spaces", Econometrica, 38: 545-569 (1970).

Scott, D. \& Suppes, P. "Fundamental Aspects of Theories of Measurement", Journal of Symbolic Logic 23: 113-128 (1958).

Subiza, B. Representaciones Numéricas de Preferencias Cuasitransitivas y Acíclicas. Tesis Doctoral. Universidad de Alicante (1992). 


\section{PUBLISHED ISSUES}

\section{FIRST PERIOD}

"A Metatheorem on the Uniqueness of a Solution"

T. Fujimoto, C. Herrero. 1984.

"Comparing Solution of Equation Systems Involving Semipositive Operators"

T. Fujimoto, C. Herrero, A. Villar. February 1985.

"Static and Dynamic Implementation of Lindahl Equilibrium"

F. Vega-Redondo. December 1984.

"Efficiency and Non-linear Pricing in Nonconvex Environments with Externalities" F. Vega-Redondo. December 1984.

"A Locally Stable Auctioneer Mechanism with Implications for the Stability of General Equilibrium Concepts"

F. Vega-Redondo. February 1985.

"Quantity Constraints as a Potential Source of Market Inestability: A General Model of Market Dynamics"

F. Vega-Redondo. March 1985.

"Increasing Returns to Scale and External Economies in Input-Output Analysis"

T. Fujimoto, A. Villar. 1985.

"Irregular Leontief-Straffa Systems and Price-Vector Behaviour"

I. Jimenez-Raneda / J.A. Silva. 1985.

"Equivalence Between Solvability and Strictly Semimonotonicity for Some Systems Involving Z-Functions"

C. Herrero, J.A. Silva. 1985.

"Equilibrium in a Non-Linear Leontief Model"

C. Herrero, A. Villar. 1985.

"Models of Unemployment, Persistent, Fair and Efficient Schemes for its Rationing" F. Vega-Redondo. 1986.

"Non-Linear Models without the Monotonicity of Input Functions"

T. Fujimoto, A. Villar. 1986.

"The Perron-Frobenius Theorem for Set Valued Mappings"

T. Fujimoto, C. Herrero. 1986.

"The Consumption of Food in Time: Hall's Life Cycle Permanent Income Assumptions and Other Models"

F. Antoñazas. 1986.

"General Leontief Models in Abstract Spaces"

T. Fujimoto, C. Herrero, A. Villar. 1986. 
"A Weak Generalization of the Frobenius Theorem"

J.A. Silva. 1986

"On the Fair Distribution of a Cake in Presence of Externalities"

A. Villar. 1987.

"A Proof of the Frobenius Theorem by Using Game Theory"

B. Subiza. 1987.

"On Distributing a Bundle of Goods Fairly"

A. Villar. 1987.

"On the Solvability of Complementarity Problems Involving Vo-Mappings and its Applications to Some Economic Models"

C. Herrero, A. Villar. 1987.

J.E. Peris. 1987.

"Complementary Problems and Economic Analysis: Three Applications"

C. Herrero, A. Villar. 1987.

"On the Solvability of Joint-Production Leontief Models"

J.E. Peris, A. Villar. 1987.

"A Characterization of Weak-Monotone Matrices"

J.E. Peris, B. Subiza. 1988.

"Intertemporal Rules with Variable Speed of Adjustment: An Application to U.K. Manufacturing Employment"

M. Burgess, J. Dolado. 1988.

"Orthogonality Test with De-Trended Data's Interpreting Monte Carlo Results using Nager Expansions"

A. Banerjee, J. Dolado, J.W. Galbraigth. 1988.

"On Lindhal Equilibria and Incentive Compatibility"

L.C. Corchón. 1988.

"Exploiting some Properties of Continuous Mappings: Lindahl Equilibria and Welfare Egalitaria Allocations in Presence of Externalities"

C. Herrero, A. Villar. 1988.

A.M. Gallego. 1990.

"On Natural Selection in Oligopolistic Markets"

L.C. Corchón. 1990. 


\section{SECOND PERIOD}

WP-AD 90-01 "Vector Mappings with Diagonal Images"

C. Herrero, A.Villar. December 1990.

WP-AD 90-02 "Langrangean Conditions for General Optimization Problems with Applications to Consumer Problems"

J.M. Gutierrez, C. Herrero. December 1990.

WP-AD 90-03 "Doubly Implementing the Ratio Correspondence with a 'Natural' Mechanism"

L.C. Corchón, S. Wilkie. December 1990.

WP-AD 90-04 "Monopoly Experimentation"

L. Samuelson, L.S. Mirman, A. Urbano. December 1990.

WP-AD 90-05 "Monopolistic Competition : Equilibrium and Optimality"

L.C. Corchón. December 1990.

WP-AD 91-01 "A Characterization of Acyclic Preferences on Countable Sets"

C. Herrero, B. Subiza. May 1991.

WP-AD 91-02 "First-Best, Second-Best and Principal-Agent Problems"

J. Lopez-Cuñat, J.A. Silva. May 1991.

WP-AD 91-03 "Market Equilibrium with Nonconvex Technologies"

A. Villar. May 1991.

WP-AD 91-04 "A Note on Tax Evasion"

L.C. Corchón. June 1991.

WP-AD 91-05 "Oligopolistic Competition Among Groups"

L.C. Corchón. June 1991.

WP-AD 91-06 "Mixed Pricing in Oligopoly with Consumer Switching Costs" A.J. Padilla. June 1991.

WP-AD 91-07 "Duopoly Experimentation: Cournot and Bertrand Competition" M.D. Alepuz, A. Urbano. December 1991.

WP-AD 91-08 "Competition and Culture in the Evolution of Economic Behavior: A Simple Example" F. Vega-Redondo. December 1991.

WP-AD 91-09 "Fixed Price and Quality Signals" L.C. Corchón. December 1991. 
WP-AD 91-10 "Technological Change and Market Structure: An Evolutionary Approach" F. Vega-Redondo. December 1991.

WP-AD 91-11 "A 'Classical' General Equilibrium Model"

A. Villar. December 1991.

WP-AD 91-12 "Robust Implementation under Alternative Information Structures" L.C. Corchón, I. Ortuño. December 1991.

WP-AD 92-01 "Inspections in Models of Adverse Selection" I. Ortuño. May 1992.

WP-AD 92-02 "A Note on the Equal-Loss Principle for Bargaining Problems" C. Herrero, M.C. Marco. May 1992.

WP-AD 92-03 "Numerical Representation of Partial Orderings" C. Herrero, B. Subiza. July 1992.

WP-AD 92-04 "Differentiability of the Value Function in Stochastic Models" A.M. Gallego. July 1992.

WP-AD 92-05 "Individually Rational Equal Loss Principle for Bargaining Problems" C. Herrero, M.C. Marco. November 1992.

WP-AD 92-06 "On the Non-Cooperative Foundations of Cooperative Bargaining" L.C. Corchón, K. Ritzberger. November 1992.

WP-AD 92-07 "Maximal Elements of Non Necessarily Acyclic Binary Relations" J.E. Peris, B. Subiza. December 1992.

WP-AD 92-08 "Non-Bayesian Learning Under Imprecise Perceptions" F. Vega-Redondo. December 1992.

WP-AD 92-09 "Distribution of Income and Aggregation of Demand" F. Marhuenda. December 1992.

WP-AD 92-10 "Multilevel Evolution in Games"

J. Canals, F. Vega-Redondo. December 1992.

WP-AD 93-01 "Introspection and Equilibrium Selection in 2x2 Matrix Games" G. Olcina, A. Urbano. May 1993.

WP-AD 93-02 "Credible Implementation"

B. Chakravorti, L. Corchón, S. Wilkie. May 1993.

WP-AD 93-03 "A Characterization of the Extended Claim-Egalitarian Solution" M.C. Marco. May 1993.

WP-AD 93-04 "Industrial Dynamics, Path-Dependence and Technological Change" F. Vega-Redondo. July 1993.

WP-AD 93-05 "Shaping Long-Run Expectations in Problems of Coordination" F. Vega-Redondo. July 1993. 
WP-AD 93-06 "On the Generic Impossibility of Truthful Behavior: A Simple Approach"

C. Beviá, L.C. Corchón. July 1993.

WP-AD 93-07 "Cournot Oligopoly with 'Almost' Identical Convex Costs"

N.S. Kukushkin. July 1993.

WP-AD 93-08 "Comparative Statics for Market Games: The Strong Concavity Case" L.C. Corchón. July 1993.

WP-AD 93-09 "Numerical Representation of Acyclic Preferences"

B. Subiza. October 1993.

WP-AD 93-10 "Dual Approaches to Utility" M. Browning. October 1993. 
